Int. J. Electrochem. Sci., 11 (2016) 9007 - 9018

\title{
High Specific Surface Area Activated Carbon with Well- Balanced Micro/Mesoporosity for Ultrahigh Supercapacitive Performance
}

\author{
Bo Hou, Tong Zhang, Rongwei Yan, De Li, Yan Mo, Lihong Yin, Yong Chen* \\ State Key Laboratory of South China Sea Marine Resource Utilisation, Hainan Provincial Key \\ Laboratory of Research on Utilization of Si-Zr-Ti Resources, Hainan University, 570228 Haikou, \\ China \\ "E-mail: ychen2002@163.com
}

doi: $10.20964 / 2016.11 .01$

Received: 15 July 2016 / Accepted: 10 September 2016 / Published: 10 October 2016

High specific surface area activated carbon derived from coconut shell was prepared using lowtemperature carbonization followed by $\mathrm{KOH}$ activation method. The resulting activated carbon exhibited excellent supercapacitance performance with an obtained specific capacitance of $325 \mathrm{~F} \mathrm{~g}^{-1}$ at $0.1 \mathrm{~A} \mathrm{~g} \mathrm{~g}^{-1}$. Moreover, the supercapacitor electrodes retained $71 \%$ of the initial capacitance at elevated current densities of $100 \mathrm{~A} \mathrm{~g}^{-1}$ and $89 \%$ after 10000 cycles when tested in $6 \mathrm{M} \mathrm{KOH}$ aqueous solution. Also, the equivalent series resistance of the system was recorded to be only $0.36 \Omega$. Meanwhile, testing of the supercapacitor electrodes in ionic liquid based-electrolyte delivered substantial specific capacitance of $198 \mathrm{~F} \mathrm{~g}^{-1}$ and an ultrahigh power density of $74.2 \mathrm{~kW} \mathrm{~kg}^{-1}$.

Keywords: Coconut shell; Supercapacitors; Pore size distribution; Power density

\section{FULL TEXT}

(C) 2016 The Authors. Published by ESG (www.electrochemsci.org). This article is an open access article distributed under the terms and conditions of the Creative Commons Attribution license (http://creativecommons.org/licenses/by/4.0/). 